\title{
Personality Types, Demographic Variables and Academic Adjustment of Fresh Undergraduates of Obafemi Awolowo University, Ile-Ife, Nigeria
}

\author{
W. O. Adeniyi. Ph. D \\ Corresponding Author, Department of Educational Foundations and Counselling, \\ Faculty of Education, Obafemi Awolowo University, lle-Ife, Nigeria \\ E-mail: oadeniyi@oauife.edu.ng, adesun223ng@yahoo.com
}

V. O. Adediran

Institute of Education, Faculty of Education, Obafemi Awolowo University, Ile-lfe, Nigeria

\section{J. 0. Okewole}

Institute of Education, Faculty of Education, Obafemi Awolowo University, Ile-Ife, Nigeria

\section{Doi:10.5901/jesr.2014.v4n6p493}

\begin{abstract}
The study ascertained the pattern of academic adjustment of students as well as the relationship between each of personality types and demographic variables and academic adjustment of students. These were with a view to providing useful recommendations on students' academic adjustment. The study adopted a descriptive survey design. The sample consisted of 600 fresh undergraduates selected from six selected faculties out of the thirteen Faculties in Obafemi Awolowo University, IleIfe, using simple random sampling technique. Thereafter, 100 (UTME and Direct entry) undergraduates were selected in each faculty using convenience sampling technique. An adapted instrument titled 'Questionnaire on Personality Types, Students' Academic Adjustment" (QPSA) was used to collect information from the students. The reliability of the instrument yielded positive results of Alphas of 0.84 and Split-half correlation of 0.87 . The data collected were analysed using simple percentage and Pearson correlation coefficient statistical methods. The results showed that $73.5 \%$ of the fresh undergraduates possessed moderate pattern of academic adjustment. It was showed that type "A" with $64.4 \%$ was the prevalent personality among the students. Furthermore, the results showed no significant relationship between personality types (A and $B)$ and students' academic adjustment $(r=0.133 ; d f=564$ at $p>0.05)$. Finally, the results showed no significant relationship between each of $\operatorname{sex}(r=-0.30 ; d f=564, p>0.05)$ and place of residence $(r=-0.029 ; d f=562, p>.05)$. It was concluded that irrespective of the personality types, most fresh undergraduates in the study area had moderate level of academic adjustment.
\end{abstract}

Keywords: Personality types, Demographic Variables, Academic Adjustment, Fresh Undergraduates

\section{Introduction}

The major aim of education is to develop human being. It is also designed to prepare an individual to live successfully. In the process of developing individuals, an opportunity should be given to enable us to overcome those problems and obstacles which we are likely to face in life. The transition to university is difficult for many students especially the fresh students. A large percentage of fresh students often find it difficult to successfully navigate this transition. Fresh students at the point of entering into the university are often uncertain of their abilities to meet up with new demands pose to them by the new environment and this is making it difficult for them to adjust.

In the modern society, life is becoming very complex and conflicting day by day. One of the major challenges facing those living in technologically advanced societies is the need to adjust to various, and sometimes conflicting, social systems such as the family, friendship networks, work or school groups. At adolescence, the conflict among the demands of several groups is likely to be particularly acute, as increasingly autonomous children struggle to gain freedom from parents, to meet teachers' demands for academic performance, to make and maintain friendships, and to 
find a place for themselves in society.If a person is well adjusted only then can one survive without psychological stress resulting from maladjustment. Therefore, adjustment is important in one's life. Adjustment during the period of adolescence will determine to a larger extent what one would be as a person and as an adult. However, it does matter what the expectations are, nearly every student encounters challenging experiences or obstacles at the beginning of university that they do not anticipate.

Positive life changes produce stress, and certainly the changes involved in leaving home for university are demanding and can lead to varying emotions including sadness, loneliness and worry (Wintre, \& Yaffe, 2000). These feelings are typical and part of the normal developmental transition to university. As students enter into university at the initial stage, they are required to face multiple transitions, including changes in their living arrangements, academic environments, and friendship networks, while adapting to greater independence and responsibility in their personal and academic lives. Although, Gall, Evans and Bellerose (2000) and Wintre and Yaffe (2000) believed that some successfully make this transition to university, Also, Sennett, Finchilescu, Gibson, and Strauss (2003) opined that is an exciting experience for some students but it is an overwhelming and stressful experience for others. While corroborating this, Wintre and Yaffe (2000) confirmed that it can be frustrating and overwhelming for many students, leading to emotional maladjustment and depression, which may, in turn, negatively affect students' performance in their academics.

In response to the above point, Kalsner and Pistole, (2003) and Kerr, Johnson, Gans, and Krumrine (2004) have established that most students who withdraw at the initial stage of entering to university often do so for inability to adjust to their new environment. While upholding the statement, Vasalampi, Salmela-Aro and Nurmi (2009) and Raju and Rahamtula (2007) confirmed that the inability of students to adjust properly in the school can lead to low academic achievement, behavioural problems, discordant educational aspirations and even school dropout. For this reason, fresh students need to be assisted to develop skills, that will enable them overcome the challenges they may encounter at the university. One way by which such students can integrate to the new environment is by adjusting themselves to the campus life.

In the meantime, the term adjustment refers to the extent to which an individual's personality functions effectively in the world of people. It refers to the harmonious relationship between the person and the environment. In other words, it is the relationship that comes among the organisms, the environment and the personality. A well adjusted personality is well prepared to play the roles which are expected of the status assigned to him within a given environment. His needs will be satisfied in accordance with the social needs.

More so, adjustment patterns are ways or methods in which different individuals adapts or becomes used to a new situation. It could also be seen as an act of slight alteration of a situation in order to achieve a correct or desired result. Baker and Siryk (1989) and Abdullah, Elias, Mahyuddin and Uli (2009) defined academic adjustment as how well students deal with educational demands. These includes; students motivation to complete academic work, success in meeting academic requirements, academic effort and satisfaction with academic environment. When an individual exhibits a form of behaviour that is below the average or expected standard required to resolve a particular problem or challenges at hand, such behaviour is considered to be in consonance with a lower level of adjustment to that particular situation. An adjustment mode that falls at average or between what can be termed low and high adjustment is referred to as being moderate, while the one that presents a higher level of response, adaptation or accommodation of a particular circumstance is termed a high level of adjustment.

Some studies have indicated that academically successful students have moderate adjustment and strong learning style preferences than low achievers and that student success is been affected by the degree to which a student engages in the school experience. For this reason, Fabian (2000) noted that when students exhibit a range of adjustment patterns associated with cooperation, initiating interaction or assertion, and self control, they are more likely to perform well in relating to their immediate environment. Engaging in the process of learning how to learn must include awareness of how self-learning styles and how material is processed. Instructors, then, can enhance a students' awareness by calling their attention to different ways to approach a given subject (McClanaghan, 2000). A significant challenge, then, is to assist students in perfecting their natural learning style while providing the incentive to develop less dominant styles they will need in the workforce and other areas of their lives.

In the opinion of Santrock (2006), individuals are likely to react differently in different situations because of the distinctive thoughts, emotions and behaviours that mark the way an individual adapts to this world. It is therefore opined that academic adjustment of an individual is a function of several variables such as individual's personality and demographics.

Everybody has a personality, and an individual's personality helps determine the limits of success, happiness and fulfilment in his/her life. Personality therefore is one of a person's most important assets, because it has already helped, 
shaped much of his/her life and will continue to do so in the future. The personality of an individual refers to a collection of emotional, thought and behavioural patterns unique to a person that is consistent overtime. It can also include an individual's thoughts, behaviour, feelings, emotions, attitudes, physique adjustment, unique learning history response patterns, habits and general poise (Denga, 2002; Jing, 2007). To Arulmani and Arulmani (2004), it is a person's unique and relatively stable patterns of behaving. It refers to particular combination of abilities, interests, values, hopes, reaction patterns, likes and dislikes, preferences and habits that make a person unique. Also, Anyin (2004) and Larsen and Buss (2005) saw it as the more or less stable and enduring organization of a person's character, temperament, intellect and physique which determines his unique adjustment to his environment. Denga (2002) stated that personality of an individual is that which tells what a man will do when placed in a given situation.

The theory of personality types contended that each of us has a natural preference which falls into one category or the other in each of the two types, Type A and Type B, and that our native personality type indicates how we are likely going to deal with different situations that life presents and in which environment we are most comfortable. There is a world outside us and there is a world inside ourselves. When we are dealing with the world of ourselves, we are "extroverting" and when we are inside ourselves, we are "introverting". People that are more extroverted than introverted tend to make decisions somewhat independently of constraints and prodding from the situation, culture, people or things around them. They may dislike being interrupted while working and may tend to forget names and faces. Extroverted persons are attuned to the culture, people and things around them, endeavouring to make decisions congruent with demands and expectations. The extroverted is outgoing, socially free, interested in variety and working with people. The extroverted may become impatient with slow tasks and does not mind being interrupted by people at times.

Lawrence (2000) opined that psychological type is just one aspect of personality (Each type represents a unique and positive personality style. As a person cannot have both type of a pair at the same time (such as turning outward in extraversion and turning inward in introversion), an assessment such as the MBTI scale can suggests which type is naturally preferred (Grutter, \& Kummerow, 2003). Having a preference does not mean that one uses the preferred pole exclusively. In healthy functioning, one has access to all eight poles and can consciously choose to override a natural preference, should the situation require it. For example, writing may require the use of introversion to focus inward and put ideas on paper. Extraverts have to suspend their natural desire to talk things through with others when they are writing; thus they are using introversion even when it is not their preference (Grutter, \& Kummerow, 2003). Jung, along with Myers, viewed type development as a life-long process. During youth, dominant and auxiliary processes are developed naturally. As individuals mature, they may begin to explore and develop lesser preferred processes (Opt, \& Loffredo, 2000). The human body constitution has a role to play on how people react to stress. Personality type is an eminent factor, which contributes or influences individuals' emotion. For example Powell (1983) who worked extensively on understanding human adjustment observed that differences found in the behavioural style of individual is as a result of constitutional factor especially activity level and sensitivity to outside events. Those that are known for their participation and interest in events going on around them which conforms to the extroverted type.

A study by Pickering (2009) supported the cognitive social learning theory that sustains many type A personalities. According to the study, type A individual places a great deal of value on their achievements and reaching their goals. The inability to meet up with goals is a great source of stress for personality type A individuals and this may affect their social relationships resulting in interpersonal conflict and ultimately having a negative effect on their physical and psychological health and well-being (Pickering, 2009).

Another problem with individuals with type $A$ is that failure to realize their set goals may lead to conflicts in the workplace. A study by Baron (1989) showed that type A people are more likely to become embroiled in conflicts with others as opposed to type B personalities. The study showed that type A experienced an elevated incidence of conflict with others when evaluated by other members of their work group.

Again, type A and type B category of adolescent exhibits different personality characteristics which has far reaching consequences on their stress, emotional dispositions and adjustments in and out of the school. The type "A" prone adolescents, according to Denga, (1994) are characterized by excessive competitive drive to accomplish more within a limited time. More so, adolescents with type A personality exhibit a chronic sense of time and internal hostility. Baron (1996), Denga, (1994) and Lyness (1993) claimed that type "A" adolescents are easily irritated, time conscious, competitive, hostile, always aggressive, impulsive, fierce, impatient, show social dominance and excess repression.

Similarly, Doctor and Doctor (1994) carried out a research with types A and B personality individuals through face to face interview. It was discovered that type A personality individuals are compulsive, workaholic, aggressive and competitive. Type B individuals are less aggressive; more relaxed and set fewer deadlines differently from traits found in type A individuals. Herbert and Cohen (1994), Melgosa (1995) and Nauhton (1997) observed that type A adolescents 
exhibit the following behaviours: struggle to do more things in less time, hostile, and aggressive. They also seem to be under the pressure of time, competitive, hasty, and very tense, constant movement; impatience, tense facial expression, roar with laughter, dissatisfied with position; want to move up; and complain frequently. They are often quiet and loud, with fluctuation and emphasis, expressive and gesticulating immediate response; give direct and brief response, hurry the speech of others, and interrupt. On the other hand, type B exhibits tranquil movement, calm, relaxed facial expression, soft smile, satisfied with position, complains, slow and soft, in speech, uniform tone, calm with few gestures, responds after pausing, gives extensive answers, listens attentively and wait to respond.

There are conflicting findings in various studies on the relationship between students' personality types and academic adjustment. For instance, some studies reported positive or negative correlations, others yet, present no association between personality types and academic adjustment. For instance, a study conducted on the subject-matter by Trapmann et al. (2007), Goldberg, (2001) and Komarraju \& karrau, (2005) reported a negative correlation between personality type B and students' adjustment to school activities. Bardi and Ryff (2007) established this fact by affirming that students with personality types B often adjust better in the school than students with personality types $A$. While explaining further, Clark and Schroth, (2010) revealed that extraversion students are more energetic spontaneous, adventurous assertive, sociable person and with positive emotions.

Another major issue in literature relates to how demographic factors such as age range, sex and place of residence influence academic adjustment of students. It is an interesting phenomenon that attempts to explain how students of different sexes achieve the characteristics they exhibit. For years, the significance of an individual sex in relation to their forms of adjustments have been subjected to enthusiastic debates, discussions and research in psychology as well as other discipline, but the difficulty of this issue is that it is scientifically difficult to determine and support.

Some researchers have reported that boys are generally more assertive and vigorous while the opinion of others differed on the issue. For instance, Joshi (1998) studied the personality adjustment among the university students. The results of the study revealed no significant effect of gender on adjustment. In the same vein, Shalu and Audichya (2006) assessed and compared the school adjustment of 60 college students (14 to 16 years) with reference to their emotional, social and educational sphere. The report showed that although boys were rated in emotional adjustment than girls. However, no significant difference was observed in school, social and educational adjustment between the two sexes. Another study conducted on a sample of 100 subjects in the age range of $17-20$ years with distribution of 50 (25 boys and 25 girls) were studied on their adjustment by Sahu (1997). Adjustment inventory for college students developed by Sinha and Singh was used for the assessment. Results showed no significant difference among boys and girls in areas of adjustments namely emotional, social, health and educational. In line with the findings of the majority of relevant studies, Kaur (2012) observed no lucid link between gender and adjustment problems among fresh undergraduates.

Contrary to the above, the result of the study on sex and academic adjustment conducted by Kenny and Rice in (1995) indicated that there were significant differences between males and females in the level of adaptation of university and was high in male-item social adjustment, while no differences sealed on other items on the scale of adjustment, due to the fact that female tend to use relationships and socialization experiences in college to adjust more than their male counterparts. This is because, females have traditionally been thought of as being more social and having a more difficult time adjusting to the college environment and making social connections than their male counterparts (Cook, 1995). Also, Pittman (2008), in his study of 79 college students, found that female students are more social isolation than their male. In their own submission, Cook (1995) and Abdullah, Elias, Mahyddin, and Uli (2009) posited that female students often have more difficult time adjusting to the colleges and/or university environment.

Also, some studies have reported that female students exhibit low social adjustment compared to male students in educational, and personal -psychological adjustments (Enochs \& Roland, 2006). This could be due to the difference in their developmental process. Female students tend to rely on relation and socialization experiences to aid in adjusting to university more than their male counter parts. However, it can be inferred from above that the differences in the adjustment levels for the groups in this study were not as high as other studies have reported. This may be due to several factors such as the changing roles of women in society, as well as the fact that more opportunities for leadership are now available for women than ever before. What is unclear is the amount of impact gender had on adjustment.

Moreover, it has also been debated whether the place of residence of students impacted on their adjustment. It is believed that fresh students need specific opportunities to integrate into university. This is to increase their academic retention rate and to assisting such students in performing well in their academic. Adams et al. (2000) remarked that, the environment in which students live has a direct impact on the student's overall adjustment. According to Dinger (1999), students who lived in environment that is conducive to learning and provided ample study space and opportunities for 
growth and interaction tend to have an easier time adjusting than students who live in other environment. Residence halt climates have been associated with families in terms of rules boundaries and atmosphere of care and concern for other members. Students are expected to develop care and concern to other in the residential halls.

Finally, the social climate has also been deemed important in assisting students to adjustment at the university. The university students belong to the category between late adolescence and early adulthood. This stage of life is characterized by periods of instability considerable conflicts, anxiety and tension (Hall. 1904). Socially, adolescence is period of building a stable identity, many young people experience role confusion and blurred self image. Student may need to be assisted to develop skills of solving these difficulties and uncertainties. Consequent upon this, the study is designed to ascertain the extent of relationship between personality types ( $A$ and $B$ ), demographic variables and academic adjustment of fresh undergraduates.

\section{Objectives of the Study}

The objectives of the study were to

a. ascertain the pattern of academic adjustment of fresh undergraduates of the Obafemi Awolowo University, lleIfe, Nigeria;

b. examine the personality type that is prevalent among the fresh undergraduates;

c. investigate the relationship between personality types (A and B) and academic adjustment of the fresh undergraduates; and

d. determine the relationship between each of sex and place of residence and academic adjustment of the fresh undergraduates.

\section{Methodology}

The study adopted a descriptive survey design. All the fresh undergraduates of the Obafemi Awolowo University, lle-Ife, Osun State, constituted the population of the study. A sample of 600 fresh undergraduates was selected from six selected faculties out of the thirteen Faculties in the school, using simple random sampling technique. Thereafter, 100 (UTME and Direct entry) undergraduates were selected in each faculty using convenience sampling technique. The instrument was administered on the fresh undergraduates in their lecture classes to those who showed interest in the questionnaire administration. An adapted instrument titled 'Questionnaire on Personality Types, Students' Academic Adjustment" (QPSA) was used to collect information from the fresh undergraduates. The QPSA was divided into three sections. Section A comprised four items on demographic variables such as part or level of student, sex, age range and place of residence. Section B comprised 22 items that sought information on the undergraduates' academic adjustment. While section $\mathrm{C}$ had 20 items and requested information on the personality type of each undergraduate. The instrument was dully validated through expert judgment and the reliability test of the instrument was also carried out. The results of the Cronbach Alpha and Spearman Brown Coefficients indicated that the instrument yielded reliability tests of Alphas of 0.84 and the Split-half correlation result of 0.87 . The results of the reliability tests authenticated that the instrument was appropriate for the study. The data collected were analysed using simple percentage and Pearson correlation coefficient statistical methods.

\section{Results}

\subsection{Research Question One}

What is the pattern of academic adjustment of fresh undergraduates of Obafemi Awolowo University, Ile-Ife, Nigeria?

Table 1: Showing Patterns of Academic Adjustment of Fresh Undergraduates of Obafemi Awolowo University, lle-Ife, Nigeria

\begin{tabular}{|c|c|c|}
\hline Academic Adjustment of Students & Frequency & Percentage (\%) \\
\hline High & 61 & 10.8 \\
\hline Moderate & 414 & 73.5 \\
\hline Low & 89 & 15.7 \\
\hline Total & $\mathbf{5 6 4}$ & $\mathbf{1 0 0}$ \\
\hline
\end{tabular}


The results in Table 1 showed that $73.5 \%$ of the fresh undergraduates had moderate pattern of academic adjustment, while, $15.7 \%$ of the students possessed low pattern of academic adjustment. The remaining $10.8 \%$ of the students possessed high pattern of academic adjustment. Arising from the results above, it can be concluded that majority of the fresh undergraduates sampled possessed moderate pattern academic adjustment.

\subsection{Research Question Two}

What is the personality type that is prevalent among fresh undergraduates of Obafemi Awolowo University, Ile-Ife, Nigeria?

Table 2: Showing Simple Percentage Analysis of Personality Types Prevalent among Fresh Undergraduates of Obafemi Awolowo University, lle-Ife, Nigeria

\begin{tabular}{|c|c|c|}
\hline Patterns of Adjustment & Frequency & Percentage (\%) \\
\hline Type A (Introversion) & 362 & 64.4 \\
\hline Type B (Extroversion) & 202 & 35.6 \\
\hline Total & $\mathbf{5 6 4}$ & 100.0 \\
\hline
\end{tabular}

Table 2 showed the responses of the fresh undergraduates on the type of personality that is prevalent among them. From the Table, the results showed that $64.4 \%$ of the fresh undergraduates possessed personality type A while the remaining $35.6 \%$ of students claimed that they had personality type B. This result showed that most fresh undergraduates in Obafemi Awolowo University had personality type A.

\subsection{Research Hypothesis One}

There is no significant relationship between personality type ( $A$ and $B$ ) and academic adjustment of fresh undergraduates of Obafemi Awolowo University, lle-Ife, Nigeria.

Table 3: Showing Pearson Correlation Coefficient of Relationship between Personality Types and Academic Adjustment of Fresh Undergraduates

\begin{tabular}{|c|c|c|c|c|c|c|c|}
\hline \multirow{2}{*}{$\begin{array}{c}\text { Academic } \\
\text { Adjustment }\end{array}$} & & Mean & S.D & N & df & r-cal & p \\
\cline { 2 - 8 } & Personality Type A & 2.0457 & .53733 & 362 & \multirow{2}{*}{564} & \multirow{2}{*}{0.133} & $>0.05$ \\
\cline { 2 - 7 } & Personality Type B & 2.0550 & .46815 & 202 & & & \\
\hline
\end{tabular}

$p>0.05$ (Not Significant)

The above Table showed the results of relationship between personality type (A and B) and academic adjustment of fresh undergraduates. From the Table, personality type A had mean and standard deviation values of 2.0457 and .53733 and personality type B possessed mean and standard deviation values of 2.0550 and .46815 respectively. The $r=0.133$; $\mathrm{df}=564$ at $p>0.05$ was found not to be significant. Hence, the findings upheld the null hypothesis which was stated that there was no significant relationship between personality types and academic adjustment of fresh undergraduates of Obafemi Awolowo University, lle-Ife.

\subsection{Research Hypothesis Two}

There is no significant relationship between sex and academic adjustment of fresh undergraduates of Obafemi Awolowo University, Ile-lfe, Nigeria.

Table 4: Showing Pearson Correlation Coefficient of Relationship between Sex and Academic Adjustment of Fresh Undergraduates

\begin{tabular}{|c|c|c|c|c|c|c|c|}
\hline \multirow{2}{*}{$\begin{array}{c}\text { Academic } \\
\text { Adjustment }\end{array}$} & & Mean & S.D & N & df & r-cal & p \\
\cline { 2 - 7 } & Male & 2.0833 & .53229 & 288 & \multirow{2}{*}{564} & \multirow{2}{*}{-0.030} & $>0.05$ \\
\cline { 2 - 6 } & Female & 2.0133 & .49136 & 276 & & \\
\hline
\end{tabular}

$p>0.05$ (Not significant) 
Table 4 above showed the Pearson analysis results of relationship between sex and academic adjustment fresh undergraduates of Obafemi Awolowo University, Ile-Ife. It was revealed that male had mean and standard deviation values of 2.0833 and .53229 , while, female possessed mean and standard deviation values of 2.0133 and .49136 respectively. The $r_{\text {cal }}$ of $-0.30 ; d f=564, p>0.05$ was not significant. This accepted the null hypothesis which stated that there was no significant relationship between sex and academic adjustment of fresh undergraduates.

\subsection{Research Hypothesis Three}

There is no significant relationship between place of residence and academic adjustment of fresh undergraduates of Obafemi Awolowo University, lle-Ife, Nigeria.

Table 5: Showing Pearson Correlation Coefficient of Relationship between Place of Residence and Academic Adjustment of Fresh Undergraduates

\begin{tabular}{|c|c|c|c|c|c|c|c|}
\hline \multirow{3}{*}{$\begin{array}{c}\text { Academic } \\
\text { Adjustment }\end{array}$} & & Mean & S.D & $\mathrm{N}$ & df & r-cal & $P$ \\
\hline & On Campus & 2.0655 & .51493 & 310 & \multirow{2}{*}{562} & \multirow{2}{*}{-0.029} & \multirow{2}{*}{$>0.05$} \\
\hline & Off Campus & 2.0149 & .52005 & 252 & & & \\
\hline
\end{tabular}

From Table 5, the mean and standard deviation values of undergraduates in On Campus were 2.0655 and .51493, while students in Off Campus had mean and standard deviation values of 2.0149 and .52005 respectively. Also, $r_{\text {cal }}=-0.029$; $\mathrm{df}=562, p>.05$ was not significant. The results implied that the null hypothesis is accepted.

\section{Discussion}

One of the major findings of this study is that it was shown that most fresh undergraduates in the study area possessed moderate level of academic adjustment. Some studies, for example, Fabian (2000) have indicated that academically successful students have moderate adjustment. In the opinion of Santrock (2006), individuals are likely to react differently in different situations because of the distinctive thoughts, emotions and behaviours that mark the way an individual adapts to this world. In an attempt to deal with stress, tension and conflict etc. the individual makes effort to maintain harmonious relationship with his/her environment. The researcher opined that a tendency exist for students to adjust to situations preferably in a manner that will not endanger or leave them at worse but rather ensure free-floating circumstances surrounding their daily activities. Deducing from above studies it has found that entering to university is considered as a time full of stress and strain. Since this will go a long way in determining their academic ability, the lecturers and other stakeholders are therefore advised to give proper attention to the problems related to adjustment among freshmen students. For new students therefore, it is again important to adjust themselves with the social climate of the university. A major task for them is to learn to manage their feelings and to express them appropriately.

Another finding of the study showed that the prevalent personality type among students is personality type A. Given the vast difference in human nature, individuals lean still be viewed as having two contrasting personalities. The high-strung personality type A with it characteristics described by Baron and Richardson (1994) as hard-driving and competitive, having a high degree of time urgency, ambitious, rigidly organized, sensitive and highly conscious confirms the prevalence of this personality type. Typically, most students responded to be high-achieving "workaholics" who multitask to ensure that their goals are met. This personality type serves as a force that drives them to do things and often become proactive and obsessed with time management. Other students that responded as personality type B possessor were relaxed, patient and easygoing. From the above, the findings of the study has provided clear evidence that most fresh undergraduates in Obafemi Awolowo University possessed personality type A.

The results emanated on the relationship between personality types also revealed that no significant relationship existed between personality type ( $\mathrm{A}$ and $\mathrm{B}$ ) and academic adjustment of fresh undergraduates. In essence, no significant influence can be attached to the personality type of an individual when assessing the way he/she adjust to situations. Previous studies on these variables have conflicting report. For instance, Trapmann, et al. (2007) and Komarraju and karrau (2005) studies revealed no association between personality types and academic adjustment. Contrarily, Bardi and Ryff (2007) established the fact that students with personality types B often adjust better in the school than students with personality types A. While supporting the argument, the duo of Clark and Schroth, (2010) revealed that extraversion students are more energetic spontaneous, adventurous assertive, sociable person and with positive emotions. However, 
Miller (2007) argued that models of personality types cannot be subjected to value judgment and that there are no better or worse, healthier or sicker type, rather each has its own inherent strength and weaknesses such that no realistic tendency exist for a prediction of each individual adjustment.

Arising from the above, it can be summarized thus, that no personality type is exclusive. Available literature on the issue revealed that everyone is partly in the introvert's world of concept and idea and partly in the extrovert's world of people and things and that most people are unconsciously more at home in one of those worlds, when challenges arise, people do their best in accordance to their preferred and constrained environment. While buttressing the fact, Grutter, and Kummerow (2003) believed that in some cases extraverts may have to suspend their natural desire to talk things through with others when they are writing; thus they are using introversion even when it is not their preference.

Also, the results from hypothesis two showed that there was no significant relationship between sex and academic adjustment of fresh undergraduates. While some studies such as Kaur (2012), Shalu and Audichya (2006) and Joshi (1998) argued that sex has no influence on academic adjustment of students, other studies Abdullah, et al. (2009), Pittman (2008), and (Cook, 1995) found that female students often have more difficult time adjusting to the university environment. Considering the fact that there was no consensus of opinion among the scholars, the inference that can be made is that, first, the difference reported between the groups may be as a result of their developmental process. For instance, female students tend to rely on relation and socialization experiences to aid in adjusting to college and/or university more than their male counter parts. However, for the researchers who indicated no differences in the adjustment levels for the groups, this may be due to several factors such as the changing roles of women in society, as well as the fact that more opportunities for leadership are being made available for women than ever before.

In conclusion, the results of the hypothesis three showed no significant relationship between place of residence and academic adjustment of fresh undergraduates. In their reaction, Adams et al. (2000) remarked that, the environment in which students live has a direct impact on the student's overall adjustment. Also supporting the statement, Dinger (1999), believed that students who lived in environment that are conducive to learning and provided ample study space and opportunities for growth and interaction tend to have an easier time adjusting than students who live in other environment. To Abdullah, et al. (2009), no difference existed between the environment where students lived and academic adjustment. Considering the disagreement that was ensued among the researchers, the basic fact is that the environment where a student finds himself places a significant role in molding his life style. Therefore, it is an undisputed fact that most students who live On Campus will have better opportunity to interact well with their colleagues in halls of residence, recreational/social centres, and religion centres, and by way of their interactions, they stand better chance of adjusting fast to the campus life than students who live Off campus.

\section{Conclusion/Recommendation}

Arising from the above findings, it can thus be concluded that most fresh undergraduates in the study area had moderate level of academic adjustment and this had predisposed them to cope well in their study. Besides, it can also be concluded that personality type of an individual student places less part in determining the adjustment pattern of student. Because it was established from the findings that personality type of an individual varies according to the environment he finds himself. However, it was believed that students who lived On Campus would have better chance of adjusting fast to campus life, because of their level of interaction with their colleagues. Finally, it was also concluded that due to changing roles or perception of women in society, there has not been a significant variation in the academic adjustment pattern of male and female.

In view of the above, it is recommended that universities should provide more accommodation and other enabling environment for the fresh students so that they can have the opportunity to interact well among their colleagues.

\section{References}

Abdullah M. C., Elias H., Mahyuddin, R. \& Uli J. (2009) Adjustment amongst first year students in a Malaysian University, European Journal of Social Sciences 8 (3).

Anyin, N. N. (2004). Personality types and career choice among senior secondary II students in Central Senatorial zone of Cross River State. Unpublished M. Ed thesis-University of Calabar, Calabar.

Ashton, M., Lee, K., Vernon, P., \& Jang, K. (2000). Fluid intelligence, crystallized intelligence, and the openness/intellect factor. Journal of Research in Personality, 34,198-207.

Baron, R. A. (1996). Essentials of Psychology. Boston, Allyn and Bacon.

De Raad, B., Perugini, M., Hrebickova, M., \& Szarota, P. (1998). Lingua franca of personality: Taxonomies and structures based on the 
psycholexical approach. Journal of Cross-Cultural Psychology, 29, 212-232.

Denga, D. I. (2002). Educational and social psychology for schools and other social organizations Calabar: CATS Publisher.

Denga, D.I \& Ekpo, T.N (1994). Executive Stress: Its Rape and Management. Calabar: Rapid Educational Publisher Ltd.

Doctor, R. M \& Doctor, J.W (1994). Stress in M.V.S. Ramachaurdrans (Ed). Encyclopedia of Human Behaviour, 4:311-323.

Fabian, H. (2000). A Seamless Transition. Paper presented at the EECERA 10th European Conference on Quality in Early Education London. August 29- September 1,2000. Frernont, J. Z. (1998). Persistence of college freshmen: Relationships among non academic attitudes and personality types, Doctoral Dissertation, Temple University, Philadelphia, PA. Pro Quest Digital Dissertations, AAT 991109.

Grutter, J., \& Kummerow, J. (2003). Using the strong interest inventory and the Myers-Briggs Type Indicator in career counseling. Career Planning and Adult. Development Journal, 19(2), 111-128.

Herbert, T.B \& Coben, S. (1994). Stress and illness. In Ramachaurdrans (Ed.), Encyclopedia of Human Behaviour. 4(r-z). Pp. 325-332.

Jing, H. E. (2007). Analysis on the relationship among test anxiety, self-concept and academic competency. In Jessica, Zoe and Bony (Eds), US-China foreign language, 48-51.

Joshi, G. (1998). A study of personality - adjustment among college students of scheduled castes and non-scheduled castes. md. Psych. Rev., 50 (2) : 78-82.

Kiuru, N., Nurmi J., Aunola K., \& Salmela-Aro, K. (2009). Peer group homogeneity in adolescents' school adjustment varies according to peer group type and gender. International Journal of Behavioral Development 33 (1) 65-76.

Larsen, R. J \& Buss, D.M 1(2005). Personality psychological domains of knowledge about human nature. 2nd (Ed.). New York: Mc Graw- Hill.

Lawrence, G. (2000). People types \& tiger stripes. Gainesville, FL: Center for Applications of Psychological Type.

Lyness, S.A. (1993). Predictor of differences between Type A and Type B Psychological Bulletin. 114: 266-295.

McClanaghan, M. E. (2000). A strategy for helping students learn how to learn. Education, 120(3), 479-468.

Opt, S. K., \& Loffredo, D. A. (2000). Rethinking communication apprehension: A Myers-Briggs perspective. Journal of Psychology, 134(5), 556-571.

Raju, M. V. \& Rahamtulla, T. K. (2007). Adjustment problems among school students Journal of the Indian Academy of Applied Psychology. 331 73- 79.

Santrock, J.W. (2006). Human adjustment. New York, Mc Graw-Hill Inc.

Shalu and Audichya, S., 2006, A study on school adjustment of rural adolescents. md. Psych. Rev., 66 (2) : 93-96.

Trapmann S, Hell B, Hirn J. W, \& Schuler H. (2007). Meta-analysis of the relationship between the Big Five and academic success at university. J. Psychol. 215:132 - 51.

Vasalampi, K. Salmela-Aro K., Nurmi, J. (2009). Adolescents self concordance, school engagement, and burnout predict their educational trajectories. European psychologist vol 14 (4). 
ISSN 2239-978X

ISSN 2240-0524
Journal of Educational and Social Research MCSER Publishing, Rome-Italy
Vol. 4 No. 6 September 2014 